\title{
EAGE
}

\section{Imaging the Subsurface Karst Morphology Using High Resolution 2D Resistivity Imaging Technique}

\author{
Zuhar Zahir Tuan Harith \\ (zuharza@petronas.com.my)
}

\begin{abstract}
A survey was carried out on a flat sandy land in the neighborhood of Gunung Datuk limestone hills complex. All 9 (NINE) boreholes drilled in this area encountered solid limestone rock at various depth ranging from 14.30 meters to 41.50 meters, indicating possible presence of karstic features. This report presents the result of 2D earth resistivity survey carried out in 2009 to provide a 3D subsurface view of the limestone head or karstic features which hopefully will help in designing the suitable foundation for any structure to be build here. Resistivity images clearly show that this area is a limestone area with karstic surface features, such as pinnacles and cavities. The depth of this zone is ranging from 8 to $35 \mathrm{~m}$. In some cases, some boreholes penetrated pinnacles, thus giving a false impression that the solid limestone is very shallow. In order to create a 3D subsurface view of the karstic limestone head, a total of 7 parallel lines were collected for each proposed site, and interestingly the results show, some of the proposed site were located directly above a possible collapsed cave (valley), thus special care need to be considered when designing the foundation of any structure to be build here structure.
\end{abstract}

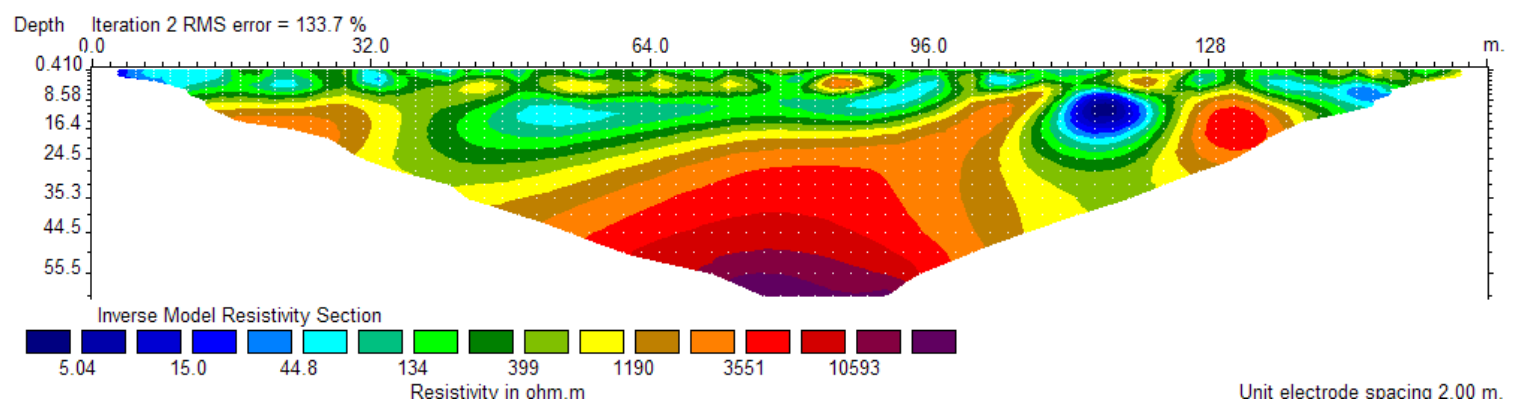

